\title{
Evaluation of anti-citrullinated type II collagen and anti-citrullinated vimentin antibodies in patients with juvenile idiopathic arthritis
}

Brooke E Gilliam ${ }^{1}$, Anil K Chauhan ${ }^{1}$ and Terry L Moore ${ }^{1,2^{*}}$

\begin{abstract}
Background: To determine the prevalence and significance of anti-citrullinated vimentin and anti-citrullinated type II collagen antibodies and elucidate their role in the disease process of juvenile idiopathic arthritis (JIA).

Methods: Sera were obtained from 95 patients with various subtypes of JIA, 19 systemic lupus erythematosus (SLE) patients, and 10 healthy children. Antibodies were measured in the sera against citrullinated and native type II collagen and vimentin (vim1-16 and vim 59-74) by enzyme-linked immunosorbent assay. Samples were compared to anti-cyclic citrullinated peptide (anti-CCP) antibody and rheumatoid factor (RF) isotypes, and our previously measured anti-citrullinated fibrinogen and a-enolase antibodies on the same patient population, in addition to erythrocyte sedimentation rate and C-reactive protein. The relationship between the anti-citrullinated antibody profile and disease activity and joint damage were also investigated.

Results: Twenty-three JIA patients (24\%) demonstrated reactivity to anti-citrullinated type II collagen. Ten JIA patients (10.5\%) demonstrated reactivity to anti-citrullinated vimentin 1-16 antibodies and 7 (7.4\%) to anti-citrullinated vimentin 59-74 antibodies. One IgM RF-positive polyarticular patient was positive for all 5 of the citrullinated autoantibodies tested. Thirty-seven different subsets of patients were identified based on their anticitrullinated autoantibody and RF isotype profile. No significant associations were noted with anti-citrullinated type II collagen and anti-citrullinated vimentin antibodies with joint damage or disease activity. Anti-citrullinated vimentin 59-74 antibodies demonstrated the highest overall specificity at $89.7 \%$, with anti-citrullinated vimentin 1-16 and anti-citrullinated type II collagen antibodies at $86.2 \%$.

Conclusion: This study demonstrates that antibodies to multiple citrullinated epitopes are present in the sera of patients with various subtypes of JIA. It also demonstrates the frequent occurrence of anti-citrullinated type II collagen and anti-citrullinated fibrinogen antibodies. The presence of autoantibodies to citrullinated antigens in JIA patients is highly diverse.
\end{abstract}

Keywords: Juvenile idiopathic arthritis, Anti-cyclic citrullinated peptide antibodies, Type II collagen, Vimentin

\footnotetext{
* Correspondence: mooretl@slu.edu

'Division of Adult and Pediatric Rheumatology, Saint Louis University School of Medicine, 1402 South Grand Blvd., Room 211A Doisy Hall, Saint Louis, Missouri 63104, USA

2Division of Adult and Pediatric Rheumatology, Internal Medicine, Pediatrics, and Molecular Microbiology and Immunology, Saint Louis University School of Medicine, Saint Louis, Missouri, USA
} 


\section{Background}

Rheumatoid arthritis (RA) and certain subtypes of juvenile idiopathic arthritis (JIA) are manifested by the formation of autoantibodies. IgM rheumatoid factor (RF), determined by the latex fixation test (LFT), is the most well-characterized autoantibody and is included in the America College of Rheumatology/European League Against Rheumatism classification criteria for RA and the International League of Associations for Rheumatology (ILAR) criteria for the IgM RF-positive polyarticular JIA subtype [1,2]. Anti-cyclic citrullinated peptide (anti-CCP) antibodies have been established as an important diagnostic tool in RA, especially in patients demonstrating a more severe, erosive disease course [3]. We and several other groups have shown that anti-CCP antibodies are present in JIA patients. They are associated with aggressive disease and manifested by various anti-CCP antibody isotypes. The IgM RF-positive polyarthritis subtype most closely resembles adult RA [4-10].

While the role of anti-CCP antibodies in RA and JIA has become better understood, the identity of the target proteins of the citrulline modification remains undetermined. Type II collagen is the most abundant protein in articular joints [11]. Type II collagen, when injected into genetically susceptible animals, induces collageninduced arthritis (CIA) and is one of the common animal models for RA [12]. Anti-Sa antibodies, which react to citrullinated vimentin are highly specific for RA [13]. Few studies have evaluated the role of anticitrullinated vimentin antibodies in JIA $[14,15]$. There are no published studies evaluating the significance of anti-citrullinated type II collagen antibodies in JIA.

The aim of this study was to investigate the presence of anti-citrullinated antibodies reactive to various modified peptide epitopes, including anti-citrullinated type II collagen and two linear peptide epitopes derived from vimentin. Combined with our previous studies on anticitrullinated fibrinogen and $\alpha$-enolase antibodies with the same JIA population [9], we attempted to determine the prevalence and significance of previously identified target proteins for citrullination and to further elucidate their role in the JIA disease pathogenesis.

\section{Methods}

\section{Patient samples}

A previously described and studied patient and control population was used for the current study [9]. Sera were collected from 95 JIA patients (77 female/18 male) from the Saint Louis University Pediatric Rheumatology outpatient clinics at the Saint Louis University Medical Center and Cardinal Glennon Children's Medical Center, following informed consent. JIA patient samples included 16 patients with IgM RF-positive polyarthritis, 36 with IgM RF-negative polyarthritis, 24 with oligoarthritis, 13 with systemic-onset arthritis, 3 with psoriatic arthritis, and 3 with enthesitis-related arthritis. All JIA patients in this study fulfilled ILAR criteria [1, 2]. JIA patient demographics are listed in Table 1. Sera from 19 childhood-onset systemic lupus erythematosus (SLE) patients (17 female/2 male) were collected from the outpatient clinics, following informed consent. The mean

Table 1 Demographic and laboratory features, given by median (interquartile range), of patients stratified by JIA subtype

\begin{tabular}{|c|c|c|c|c|c|c|c|}
\hline & $\begin{array}{l}\text { JIA } \\
n=95\end{array}$ & $\begin{array}{l}\text { IgM RF+ } \\
\text { polyarthritis } \\
n=16\end{array}$ & $\begin{array}{l}\text { lgM RF- } \\
\text { polyarthritis } \\
n=36\end{array}$ & $\begin{array}{l}\text { Oligoarthritis } \\
n=24\end{array}$ & $\begin{array}{l}\text { Systemic } \\
\text { arthritis } \\
n=13\end{array}$ & $\begin{array}{l}\text { Psoriatic } \\
\text { arthritis } \\
n=3\end{array}$ & $\begin{array}{l}\text { Enthesitis-related } \\
\text { arthritis } \\
n=3\end{array}$ \\
\hline Sex, no. females/males & $77 / 18$ & $14 / 2$ & $30 / 6$ & $22 / 2$ & $8 / 5$ & $3 / 0$ & $0 / 3$ \\
\hline Age, median (IQ range) & $\begin{array}{l}12(5- \\
16)\end{array}$ & $14.5(9.8-16)$ & $12(5.3-15.5)$ & $10(4.3-12)$ & $10.5(4.8-14.3)$ & $17(15-17)^{*}$ & $16(5-17)^{*}$ \\
\hline $\begin{array}{l}\text { Disease duration, median (IQ } \\
\text { range) }\end{array}$ & $\begin{array}{l}2(0.5- \\
6.5)\end{array}$ & $0.5(0.4-5.1)$ & $2.3(0.6-6)$ & $2(0.6-8.1)$ & $3.8(1-9.5)$ & $4(0-8)^{*}$ & $2.5(1-7)^{*}$ \\
\hline $\begin{array}{l}\text { Tender/swollen joint count, } \\
\text { median (IQ range) }\end{array}$ & $8(2-10)$ & $10(8-13)$ & $8(6-12)$ & $1(1-2)$ & $9(1-22)$ & $2(1-8)^{*}$ & $2(1-2)^{*}$ \\
\hline $\begin{array}{l}\text { No. patients with joint damage } \\
(\%)\end{array}$ & $\begin{array}{l}20 \\
(20.8)\end{array}$ & $5(31.3)$ & $10(27.8)$ & $1(4.2)$ & $4(30.8)$ & $0(0.0)$ & $0(0.0)$ \\
\hline CRP, median (IQ range) mg/dl & $\begin{array}{l}0.7(0.3- \\
1.9)\end{array}$ & $2.6(0.8-13.3)$ & $0.80(0.3-4.8)$ & $0.8(0.3-5.5)$ & $4.9(2.2-16.3)$ & $0.7(0.33-2.1)^{*}$ & $0.4(0.3-2.7)^{*}$ \\
\hline (\% positive) & $(36.8)$ & $(50.0)$ & $(33.3)$ & $(25.0)$ & $(29.2)$ & $(33.3)$ & $(33.3)$ \\
\hline ESR, median (IQ range) $\mathrm{mm} / \mathrm{hr}$ & $\begin{array}{l}16(7- \\
37)\end{array}$ & $20(8-31)$ & $14(7-32)$ & $15(7-31)$ & $30(7-50)$ & $6(6-32)^{*}$ & $7(2-7)^{*}$ \\
\hline (\% positive) & $(50.5)$ & $(68.8)$ & $(44.4)$ & $(45.8)$ & $(69.2)$ & (33.3) & $(0.0)$ \\
\hline
\end{tabular}

CRP: C-reactive protein; ESR: Erythrocyte sedimentation rate.

Cut-points for a positive value: CRP ( $\geq 0.8 \mathrm{mg} / \mathrm{dl}), \operatorname{ESR}(\geq 15 \mathrm{~mm} / \mathrm{hr})$. *range is given due to small sample size. 
age of the SLE patients was $15.7 \pm 3.1$ years and the mean disease duration was $2.7 \pm 3.2$ years. Sera were also collected from 10 healthy children ( 9 female/ 1 male) at the well-child clinic at Cardinal Glennon Children's Medical Center, following informed consent. The mean age for the healthy children was $14.0 \pm 5.9$ years. The study was approved by the Institutional Review Board of the Saint Louis University Medical Center.

At the time of sample collection, 38 JIA patients were taking non-steroidal anti-inflammatory drugs [33 on naproxen, 2 on nabumetone, one on diclofenac, one on celecoxib, and one on tolmetin], 35 were taking disease modifying anti-rheumatic drugs [31 on methotrexate, 2 on leflunomide, and 2 on sulfasalazine], 15 were treated with biologics [12 with etanercept, one with infliximab, one with abatacept, and one with anakinra], 9 JIA patients were taking hydroxychloroquine, 6 patients were taking prednisone, and one was taking prednisolone. Eighteen JIA patients were not taking any medication at the time of sample collection, as this was either their initial visit to the rheumatology clinic or they had been lost to follow up and later returned to the clinic.

\section{Laboratory and clinical evaluation}

Erythrocyte sedimentation rate (ESR) was determined by modified Westergren technique and considered elevated at $\geq 15 \mathrm{~mm} / \mathrm{hr}$. C-reactive protein (CRP) was determined by electroimmunoassay and a value of $\geq 0.8$ $\mathrm{mg} / \mathrm{dl}$ was considered elevated. Initial determination of IgM RF positivity was performed using the latex fixation test (LFT), which is how seropositive JIA patients were classified. The QUANTA-Lite RF ELISA (INOVA Diagnostics, Inc., San Diego, CA) was used for detection of IgA and IgM RF following manufacturer's instructions. The cut-off value for positive IgA or IgM RF was $6 \mathrm{U}$. A third generation anti-CCP antibody test, the QUANTA-Lite CCP3 ELISA (INOVA Diagnostics, Inc.) was used for detection of IgG anti-CCP antibodies according to manufacturer's instructions. The cut-off value for a positive result was $20 \mathrm{U}$. IgA and IgM antiCCP antibodies were measured as previously described [10]. Cut-off values for a positive result were calculated at optical density $(\mathrm{OD})=0.16$ and $\mathrm{OD}=0.43$, respectively.

Sixty-six JIA patients had active disease at the time of sample collection and 29 were in disease remission. Clinical data regarding signs of active disease (including joint pain and swelling, limitations of range of motion, fever, rash, visceral involvement, and inflammatory markers) were collected from patient records of the Pediatric Rheumatology clinics. Joint damage was noted in 20/95 JIA patients. Radiological data was evaluated for signs of joint damage (defined as joint space narrowing and/or erosions) by musculoskeletal radiologists and reviewed by pediatric rheumatologists. Both clinical and laboratory data were collected from the same time period as sera were collected.

\section{In vitro deimination of type II collagen}

Type 2 rabbit skeletal muscle peptidyl arginine deiminase (PAD) (Sigma, Saint Louis, MO) was used for enzymatic treatment of human type II collagen (Chondrex, Redmond, VA) following a previously described protocol [16]. Human type II collagen was incubated at a concentration of $20 \mu \mathrm{g} / \mathrm{ml}$ with $2 \mathrm{U} / \mathrm{ml} \mathrm{PAD}$ at $37^{\circ} \mathrm{C}$ for 18 hours in a buffer of $20 \mathrm{mM}$ Hepes (pH 8.8), $0.3 \mathrm{M}$ $\mathrm{NaCl}, 1 \mathrm{mM}$ EDTA, $1 \mathrm{mM}$ dithiothreitol (DTT), and $10 \mathrm{mM} \mathrm{CaCl}$. EDTA was added to stop the reaction (10 mM final concentration).

\section{Citrullinated and native autoantibody ELISAs}

The ELISA for measurement of anti-citrullinated type II collagen antibodies was performed as previously described, with modifications [16]. Briefly, 96-well microtitre plates (Nunc, Roskilde, Denmark) were coated with native or citrullinated type II collagen $(10 \mu \mathrm{g} / \mathrm{ml})$ and blocked with $2 \%$ bovine serum albumin (BSA) in phosphate buffered saline (PBS) for one hour at $4{ }^{\circ} \mathrm{C}$, followed by three washes with PBS/0.05\% Tween. Sera were diluted 1:50 in radioimmunoassay (RIA) buffer (1\% BSA, $350 \mathrm{mM} \mathrm{NaCl}, 10 \mathrm{mM}$ Tris-HCl pH 7.6, 1\% vol/vol Triton X-100, $0.5 \%$ wt/vol Na-deoxycholate, $0.1 \%$ SDS) added to the wells in duplicate, and incubated for two hours at room temperature (RT) with gentle agitation. After 3 washes with PBS/0.05\% Tween, goat anti-human IgG horseradish peroxidase (HRP) (Antibodies Incorporated, Davis, CA) diluted in RIA buffer was added to the wells at a concentration of 1:10,000 and incubated for one hour at RT. After a final wash step, bound antibodies were detected with tetramethylbenzidine (TMB), an HRP substrate (BioFX, Owing Mills, Maryland), and the reaction was stopped with the addition of $0.25 \mathrm{M} \mathrm{H}_{2} \mathrm{SO}_{4}$. The absorbance was measured at $450 \mathrm{~nm}$ (Tecan Group Ltd., Männedorf, Switzerland). Patient results from duplicate wells were averaged and the OD from blank wells containing PBS $/ 0.05 \%$ Tween were subtracted from the average. Serum was considered positive if the titer reached two standard deviations (SD) above the mean for healthy controls. Positive cut-off points were OD $=3.03$ for anti-citrullinated type II collagen antibodies and $\mathrm{OD}=3.3$ for native type II collagen .

Antibodies against the citrullinated and native form of two linear peptides derived from vimentin ((Vim) amino acids (aa) 1-16 STCitS VSSS SYCitCit MFGG and Vim aa 59-74 VYAT CitSSA VCitLCit SSVP) were determined by ELISA, as previously described [17]. For native vimentin, arginine replaced citrulline for each peptide sequence. The vimentin epitopes used have 
been frequently recognized by serum from anti-CCP antibody positive RA patients with longstanding disease [17]. Briefly, 96-well microtitre plates were coated with native or citrullinated vimentin peptide $(10 \mu \mathrm{g} / \mathrm{ml})$ in $\mathrm{PBS} / 0.1 \%$ BSA and incubated overnight at $4^{\circ} \mathrm{C}$. Sera were diluted 1:100 in PBS/1\% BSA/0.05\% Tween, added in duplicate, and incubated for 60 minutes at $37^{\circ} \mathrm{C}$ with gentle agitation. After three washes with $\mathrm{PBS} / 0.05 \%$ Tween, rabbit anti-human IgG HRP (Antibodies Incorporated) diluted in RIA buffer was added to the wells at a concentration of 1:10,000 and incubated for one hour. After a final wash step, bound antibodies were detected with $\mathrm{TMB}$, and the reaction was stopped with the addition of $0.25 \mathrm{M} \mathrm{H}_{2} \mathrm{SO}_{4}$. The absorbance was measured at $450 \mathrm{~nm}$. Patient results from the duplicate wells were averaged and the OD from a blank well containing $\mathrm{PBS} / 0.05 \%$ Tween was subtracted from the average. Serum was considered positive if the titer reached two SD above the mean for healthy controls. Positive cut-off points were $\mathrm{OD}=0.79$ for anti-citrullinated vimentin aa $1-16$ antibodies and $\mathrm{OD}=1.3$ for native vimentin aa $1-16$. Positive cut-off points were OD $=0.81$ for anti-citrullinated vimentin aa 59-74 antibodies and $\mathrm{OD}=0.83$ for native vimentin aa $59-74$.

\section{Statistical analysis}

Patient groups were compared using Student's t test and $\mathrm{X}^{2}$ test for proportions. For tables with cells with small frequencies, Fisher's exact test was used. Correlations were analyzed by Spearman's rho correlation coefficient. Correlations were described as either strong $(>0.7)$, moderate $(0.7-0.5)$, fair $(0.49-0.3)$, or poor $(<0.3)$. The sensitivity, specificity, and positive predictive value (PPV) of citrullinated type II collagen, and citrullinated vimentin aa 1-16 and aa 59-74 were calculated in the JIA population. The sensitivity expresses the percentage of JIA patients positive for the test and specificity expresses the frequency of negative tests in the absence of JIA or JIA subtypes. PPV describes the group of patients with a positive test result who are correctly diagnosed. Statistical analyses were carried out using SPSS version 19.0 (Chicago, IL). A p-value $<0.05$ was considered statistically significant.

\section{Results}

JIA serum reactivity to native and citrullinated type II collagen and vimentin

Twenty-three JIA patients (24.2\%) showed reactivity to citrullinated type II collagen (Table 2). IgM RF-negative polyarthritis and oligoarthritis patients demonstrated the highest level of reactivity against citrullinated type II collagen (Table 2). Twelve of the 23 (52.2\%) JIA patients positive for anti-citrullinated type II collagen antibodies were also positive for IgM RF, which was measured by ELISA, but only in two that were positive by LFT. Seventeen (17.9\%) JIA patients reacted with native type II collagen, including one with psoriatic arthritis, 2 with IgM RF-positive polyarthritis, 7 with IgM RF-negative polyarthritis, and 7 with oligoarthritis. Thirteen of 23 (56.5\%) for JIA patients positive for citrullinated type II collagen antibodies were also positive for native type II collagen antibodies. Three SLE patients (15.8\%) and one

Table 2 Anti-citrullinated type II collagen and vimentin antibody concentration and positivity in JIA subtypes (n=95)

\begin{tabular}{|c|c|c|c|c|c|c|}
\hline & $\begin{array}{l}\text { Poly RF+ } \\
n=16\end{array}$ & $\begin{array}{l}\text { Poly RF- } \\
n=36\end{array}$ & $\begin{array}{l}\text { Oligo } \\
n=24\end{array}$ & $\begin{array}{l}\text { Systemic } \\
n=13\end{array}$ & $\begin{array}{l}\text { Enthesitis } \\
n=3\end{array}$ & $\begin{array}{l}\text { Psoriatic } \\
n=3\end{array}$ \\
\hline & Mean $\pm S D$ & Mean $\pm S D$ & Mean $\pm S D$ & Mean $\pm S D$ & Mean $\pm S D$ & Mean \pm SD \\
\hline Citrullinated Type II Collagen (OD) & $1.7 \pm 0.77$ & $2.0 \pm 1.0$ & $2.4 \pm 0.76$ & $1.9 \pm 1.0$ & $3.0 \pm 0.32$ & $1.5 \pm 1.7$ \\
\hline Positivity n(\%) & $2(12.5 \%)$ & $9(25 \%)$ & $7(29.2 \%)$ & $2(15.4 \%)$ & $2(66.7 \%)$ & $1(33.3 \%)$ \\
\hline Native Type II Collagen (OD) & $1.4 \pm 0.82$ & $1.8 \pm 1.1$ & $2.4 \pm 0.97$ & $1.5 \pm 0.78$ & $2.4 \pm 0.60$ & $1.4 \pm 1.7$ \\
\hline Postivity n(\%) & $2(12.5 \%)$ & $7(19.4 \%)$ & $7(29.2 \%)$ & $0(0 \%)$ & $0(0 \%)$ & $1(33.3 \%)$ \\
\hline Citrullinated Vimentin 1-16 (OD) & $0.63 \pm 0.79$ & $0.47 \pm 0.17$ & $0.45 \pm 0.30$ & $0.49 \pm 0.25$ & $0.38 \pm 0.12$ & $0.34 \pm 0.08$ \\
\hline Positivity n(\%) & $1(6.25 \%)$ & $3(8.3 \%)$ & $3(12.5 \%)$ & $3(23.1 \%)$ & $0(0 \%)$ & $0(0 \%)$ \\
\hline Native Vimentin 1-16 (OD) & $0.67 \pm 0.80$ & $0.50 \pm 0.17$ & $0.47 \pm 0.29$ & $0.55 \pm 0.26$ & $0.42 \pm 0.12$ & $0.35 \pm 0.07$ \\
\hline Positivity n(\%) & $1(6.25 \%)$ & $0(0 \%)$ & $1(4.2 \%)$ & $0(0 \%)$ & $0(0 \%)$ & $0(0 \%)$ \\
\hline Citrullinated Vimentin 59-74 (OD) & $0.74 \pm 0.80$ & $0.55 \pm 0.22$ & $0.51 \pm 0.24$ & $0.46 \pm 0.2$ & $0.45 \pm 0.12$ & $0.36 \pm 0.1$ \\
\hline Positivity n(\%) & $2(12.5 \%)$ & $2(5.6 \%)$ & $2(8.3 \%)$ & $1(7.7 \%)$ & $0(0 \%)$ & $0(0 \%)$ \\
\hline Native Vimentin 59-74 (OD) & $0.69 \pm 0.82$ & $0.44 \pm 0.20$ & $0.38 \pm 0.22$ & $0.42 \pm 0.18$ & $0.26 \pm 0.11$ & $0.29 \pm 0.05$ \\
\hline Positivity n(\%) & $1(6.25 \%)$ & $1(2.8 \%)$ & $1(4.2 \%)$ & $0(0 \%)$ & $0(0 \%)$ & $0(0 \%)$ \\
\hline
\end{tabular}

Continuous variables are expressed as means \pm SD. $N$ : Number of patients; OD: Optical density; RF: Rheumatoid factor. Cut points for positive values: Anti-citrullinated type II collagen antibodies $(O D \geq 3.03)$, Native type II collagen antibodies $(O D \geq 3.3)$, anti-citrullinated vimentin $1-16$ antibodies $(O D \geq 0.79)$, native vimentin 1-16 antibodies (OD $\geq 1.3$ ), anti-citrullinated vimentin $59-74$ antibodies $(O D \geq 0.81)$, native vimentin $59-74$ antibodies (OD $\geq 0.83$ ). 
healthy child (10.0\%) were positive for citrullinated type II collagen, while 1 SLE patient (5.3\%) and none of the healthy children reacted with native type II collagen.

Ten JIA patients (10.5\%) were considered positive for anti-citrullinated vimentin aa 1-16 antibodies and seven (7.4\%) were positive for anti-citrullinated vimentin aa 59-74 antibodies (Table 2). Four of the 10 (40.0\%) JIA patients' positive for anti-citrullinated vimentin aa 1-16 antibodies and $6 / 7$ positive for anti-citrullinated vimentin aa 59-74 antibodies (85.7\%) were also positive for IgM RF. Positivity for anti-citrullinated vimentin antibodies were found in all JIA subtypes, except psoriatic and enthesitis-related JIA. Two (2.1\%) JIA patients reacted with native vimentin aa $1-16$, including one with IgM RF-positive polyarthritis, one with IgM RF-negative polyarthritis and one with oligoarthritis. Three (3.2\%) JIA patients reacted with native vimentin aa 59-74, including one with IgM RF-positive polyarthritis and one with oligoarthritis. All JIA patients positive for native vimentin antibodies were also positive for citrullinated vimentin antibodies. Four (21.1\%) SLE patients reacted with citrullinated vimentin aa $1-16$, while two $(10.5 \%)$ reacted with native vimentin aa 1-16. None of the healthy individuals reacted with citrullinated vimentin aa 1-16 and two
(20.0\%) were positive for native vimentin aa $1-16$. Anticitrullinated vimentin aa 59-74 antibodies were found in $3(15.8 \%)$ SLE patients and none of the healthy individuals. Three SLE (15.8\%) and three healthy children (30.0\%) reacted with native vimentin aa 59-74.

One oligoarthritis patient was positive for anticitrullinated type II collagen antibodies, and both anticitrullinated vimentin aa $1-16$ and aa 59-74. When all citrullinated autoantibodies were considered, including anti-citrullinated fibrinogen and $\alpha$-enolase antibodies, measured in our previously published study [9], one IgM RF-positive polyarthritis patient reacted to all 5 of the anti-citrullinated autoantibodies tested.

\section{Commonality between anti-citrullinated antibody reactivities in JIA}

Antibodies against various citrullinated proteins may be present in the sera at the same time. Thirty-seven different subsets of patients were identified based on their anti-citrullinated autoantibody and RF isotype profile, in addition to a group who were negative for all measured autoantibodies (Figure 1). IgM RF positivity alone was observed most frequently $(\mathrm{n}=12)$, followed by both IgM $\mathrm{RF} / \mathrm{IgM}$ anti-CCP antibody positivity $(\mathrm{n}=5)$ and IgG

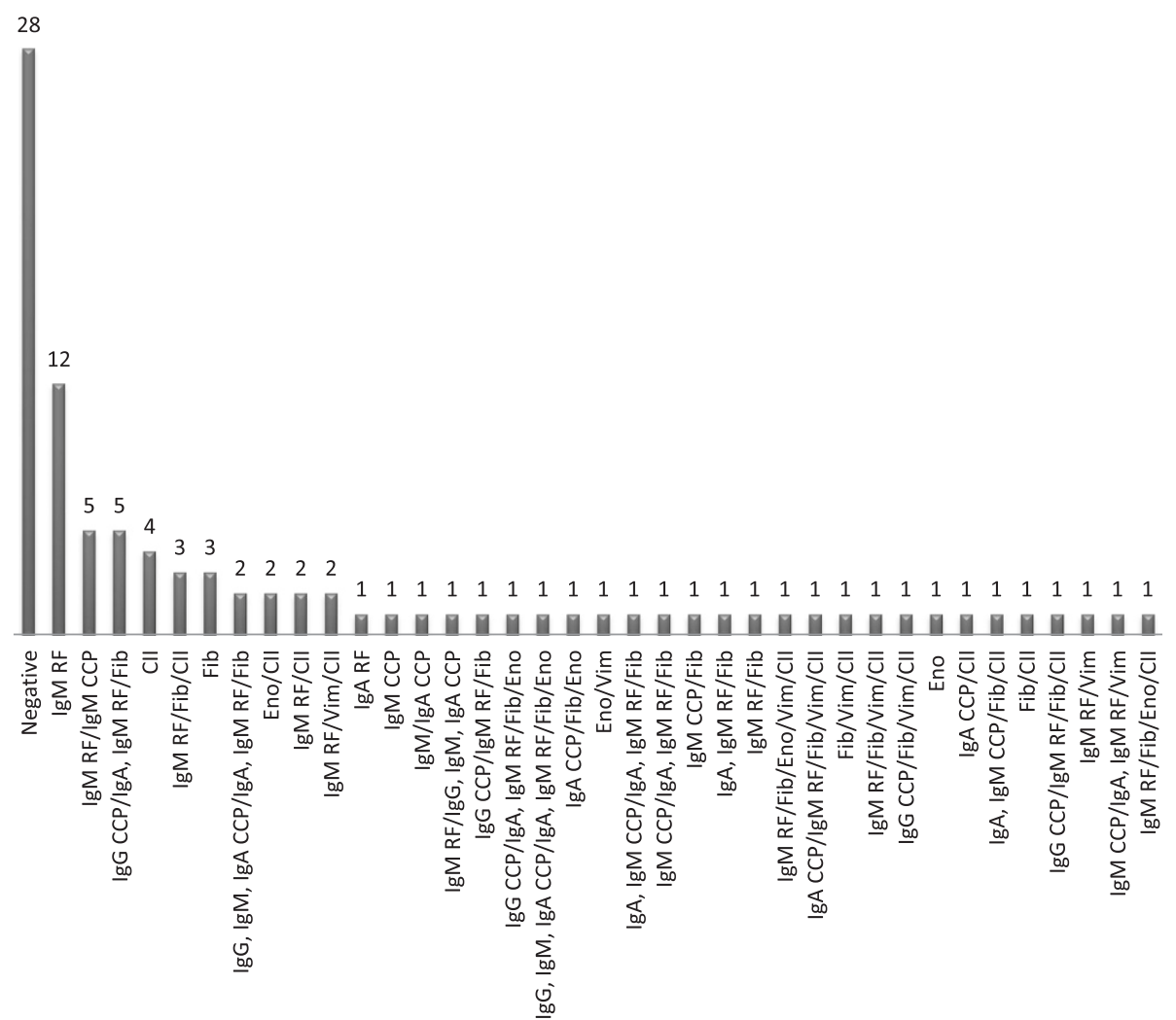

Figure 1 Patterns of citrullinated antibody reactivity in JIA sera ( $\mathbf{n = 9 5 ) . ~ C l l : ~ a n t i - c i t r u l l i n a t e d ~ t y p e ~ I I ~ c o l l a g e n ~ a n t i b o d i e s ; ~ C C P : ~ c y c l i c ~}$ citrullinated peptide; Eno: anti-citrullinated a-enolase antibodies; Fib: anti-citrullinated fibrinogen antibodies; RF: rheumatoid factor; Vim: anticitrullinated vimentin (aa1-16 and aa59-74) antibodies. 
anti-CCP antibodies/IgA and IgM RF/anti-citrullinated fibrinogen antibody positivity $(n=5)$.

\section{Serological correlations}

Anti-citrullinated type II collagen antibodies demonstrated a fair correlation with anti-citrullinated vimentin aa $1-16$ and aa 59-74, anti-citrullinated $\alpha$-enolase antibodies, and anti-citrullinated fibrinogen antibodies (Table 3). Anti-citrullinated vimentin aa 1-16 also correlated strongly with anti-citrullinated vimentin aa 59-74 $(\mathrm{r}=0.96, \mathrm{p}<0.001)$.

Anti-citrullinated vimentin aa 1-16 and aa 59-74 antibodies correlated significantly with IgM anti-CCP antibodies $(\mathrm{r}=0.24, \mathrm{p}=0.01$ and $\mathrm{r}=0.22, \mathrm{p}=0.018$, respectively) and $\operatorname{IgA}$ anti-CCP antibodies $(r=0.26$, $\mathrm{p}=0.006$ and $0.23, \mathrm{p}=0.014$, respectively), though the correlation was poor. IgG anti-CCP antibodies correlated significantly with anti-citrullinated vimentin aa $1-16(\mathrm{r}=0.33, \mathrm{p}<0.001)$, anti-citrullinated vimentin aa 59-74 $(\mathrm{r}=0.22, \mathrm{p}=0.022)$, and citrullinated type II collagen $(r=0.21, p=0.026)$. IgM RF demonstrated a significant but poor correlation with anti-citrullinated vimentin aa $1-16(\mathrm{r}=0.26, \mathrm{p}=0.006)$ and anti-citrullinated vimentin aa 59-74 $(\mathrm{r}=0.23, \mathrm{p}=0.014)$. Anti-citrullinated vimentin aa $1-16$ also correlated significantly with $\operatorname{IgA} \operatorname{RF}(r=0.22$, $\mathrm{p}=0.017)$.

\section{Relationship between serological markers and disease course}

JIA patients with joint damage were positive for various combinations of anti-citrullinated antibodies, with IgG anti-CCP and anti-citrullinated fibrinogen antibody positivity demonstrated in 7/20 (35\%) patients with joint damage (Figure 2). Anti-citrullinated type II collagen antibodies and anti-citrullinated vimentin aa 1-16 and aa 59-74 antibodies were not significantly elevated in JIA patients with joint damage compared to those with no joint damage. When evaluating the relationship between the autoantibody profile and the number of joints damaged in JIA patients, a correlation was noted with IgA RF ( $\mathrm{r}=0.38, \mathrm{p}=0.001), \operatorname{IgM} \operatorname{RF}(\mathrm{r}=0.43, \mathrm{p}<0.001)$, anti-citrullinated fibrinogen antibodies $(\mathrm{r}=0.33, \mathrm{p}=0.006)$, and IgA and IgG anti-CCP antibodies $(\mathrm{r}=0.26$ and $\mathrm{r}=0.27$, respectively, $\mathrm{p}<0.028)$. Levels of $\operatorname{IgA}(\mathrm{OD}=0.17$ vs. $\mathrm{OD}=0.04)$, IgG ( $46 \mathrm{U}$ vs. $5 \mathrm{U})$, and $\operatorname{IgM}(\mathrm{OD}=0.61$ vs. $\mathrm{OD}=0.24)$ anti-CCP antibodies, IgA (9U vs. $1 \mathrm{U})$ and IgM (32U vs. 6U) RF, and anti-citrullinated fibrinogen $(\mathrm{OD}=0.95$ vs. $\mathrm{OD}=0.45)$ were significantly higher in patients with more 5 or more joints damaged compared to those with less than 5 joints damaged, respectively $(\mathrm{p}<0.03)$. No significant differences were noted for anticitrullinated vimentin or type II collagen when evaluating the number of joints damaged in JIA patients. Nearly $50 \%$ of JIA patients with joint damage did not show any positivity for the antibodies tested (Figure 2).

It was noted that anti-citrullinated vimentin aa 1-16 antibodies demonstrated a faircorrelation with ESR $(\mathrm{r}=0.33, \mathrm{p}=0.001)$. ESR levels were significantly elevated in JIA patients that were positive for anti-citrullinated vimentin aa $1-16$ antibodies $(46 \mathrm{~mm} / \mathrm{hr}$ ) compared to those who were negative $(25 \mathrm{~mm} / \mathrm{hr} ; \mathrm{p}=0.04)$.

\section{Sensitivity and Specificity of anti-citrullinated vimentin and type II collagen antibodies for JIA}

The sensitivity, specificity, and PPV of anti-citrullinated vimentin aa 1-16 and aa 59-74 antibodies and anticitrullinated type II collagen antibodies are shown in Table 4. Sensitivities, specificities, and PPVs were calculated for the overall JIA population and for each subtype, excluding enthesitis-related JIA and psoriatic JIA due to small samples size. Overall sensitivities for these parameters ranged from $7.8 \%$ to $25.8 \%$ and specificities from $86.2 \%$ to $89.7 \%$. As with the sensitivities for JIA overall, sensitivities for anti-citrullinated type II collagen and vimentin antibodies in each JIA subtype remained low. Specificities were particularly high for anti-citrullinated vimentin aa 59-74 antibodies for all JIA subtypes included in this analysis (Table 4).

\section{Discussion}

Several studies have attempted to identify the citrullination targets of proteins in RA and JIA [9, 18]. We previously evaluated sera from JIA patients for the presence of antibodies to citrullinated fibrinogen and

Table 3 Correlations between the panel of citrullinated autoantibodies and anti-CCP antibody isotypes

\begin{tabular}{llllllll}
\hline & Vimentin 1-16 & Vimentin 59-74 & a-Enolase & Fibrinogen & IgG CCP & IgA CCP & IgM CCP \\
\hline Type II Collagen & $0.41^{* *}$ & $0.47^{* *}$ & $0.31^{* *}$ & $0.45^{* *}$ & $0.21^{*}$ & $0.22^{*}$ & NS \\
Vimentin 1-16 & & $0.96^{* *}$ & $0.39^{* *}$ & $0.42^{* *}$ & $0.33^{* *}$ & $0.26^{*}$ & $0.24^{*}$ \\
Vimentin 59-74 & & & $0.35^{* *}$ & $0.39^{* *}$ & $0.22^{*}$ & $0.23^{*}$ & $0.22^{*}$ \\
a-Enolase & & & $0.30^{*}$ & $0.24^{*}$ & $0.29^{*}$ & NS \\
Fibrinogen & & & & & $0.47^{* *}$ & $0.28^{*}$ & NS \\
IgG CCP & & & & & & $0.34^{* *}$ & NS \\
IgA CCP & & & & & & & \\
\hline
\end{tabular}

CCP: Cyclic citrullinated peptide. P-value $<0.05$ indicated by ${ }^{*}$, p-value $<0.001$ indicated by **. 


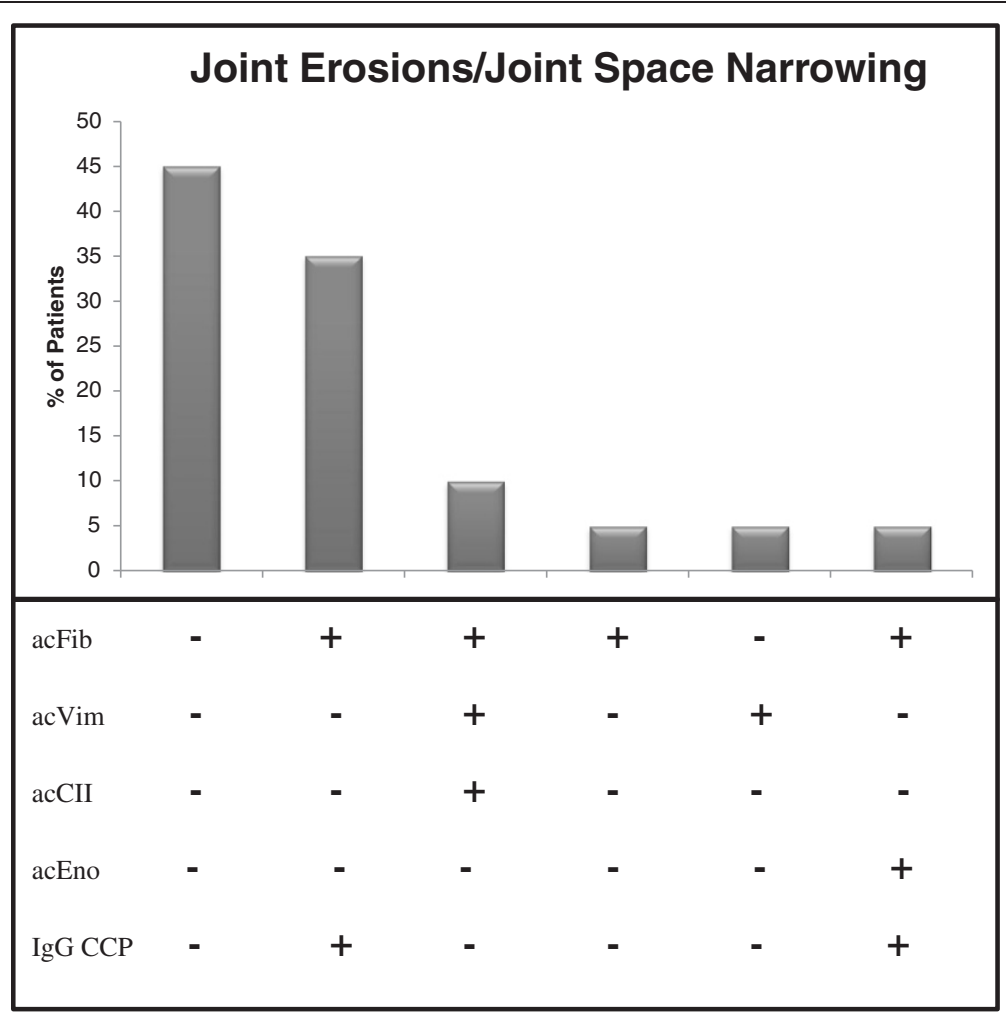

Figure 2 Percentage of JIA patients with radiographic progression $(n=20)$ based on their anti-citrullinated antibody profile. acCll: anticitrullinated type II collagen antibodies; acEno: anti-citrullinated a-enolase antibodies; acFib: anti-citrullinated fibrinogen antibodies; acVim: anticitrullinated vimentin (aa1-16 and aa59-74) antibodies; CCP: cyclic citrullinated peptide.

$\alpha$-enolase [9]. Both of these proteins are targets of the citrulline modification in RA [18-21]. In the present study, we built on this evaluation by further analyzing for the presence of anti-citrullinated type II collagen and vimentin antibodies.

The prevalence of anti-citrullinated vimentin antibodies in our JIA cohort was similar to the findings in two other studies, with positivity in $5.4 \%$ and $8.9 \%$ of their JIA population $[14,15]$. Of note, the two studies evaluating anti-citrullinated vimentin antibodies in JIA used the commercially available anti-mutated citrullinated vimentin (MCV) ELISA (Orgentec, Mainz, Germany), producing similar results to the present study, using linear peptides derived from vimentin. Morbach et al. [15] reported sensitivity for anti-MCV antibodies for the diagnosis of IgM RF-positive polyarthritis to be $83.3 \%$ with specificity at $91.1 \%$. The specificity in the present study $(89.7 \%$ 86.2\%) was comparable to that reported by Morbach et al. [15]; however, the sensitivity of their results was substantially higher. This observed difference in sensitivities may be due to different assays used for measurement of anti-citrullinated vimentin antibodies. However, Snir et al. [18] noted a high correlation between antibody responses to MCV and citrullinated vimentin peptides in both serum and synovial fluid.
The presence of anti-citrullinated vimentin antibodies did not correlate with radiological progression or disease activity in this JIA cohort; however, a fair correlation was made between anti-citrullinated vimentin aa 1-16 antibodies and ESR.Kuna et al. [14] reported no correlations between anti-MCV antibodies and ESR, tender/swollen joint count, or the Sharp score. However, Innala et al. [22] found that anti-MCV antibodies best identified patients with early RA who had persistent inflammatory activity, measured by Disease Activity Score (DAS)28, ESR, CRP and swollen joint count when compared to other antibodies against citrullinated peptide proteins. The same study noted no difference in predicting radiographic progression by measuring anti-MCV antibodies, second and third generation anti-CCP antibodies, IgA/ IgG anti-CCP antibodies, or IgM RF [22], similar to findings by van der Linden et al [23].

The most commonly used mouse model for adult RA, CIA, uses immunization with type II collagen to induce arthritis [12]. However, only a small number of studies have analyzed the autoimmune response to native type II collagen in JIA and its potential to tolerize animals via oral administration of type II collagen [24-26]. Lindsley et al. [24] showed that antibodies to native type II collagen could be found in 33\% of oligoarticular JIA 
Table 4 Sensitivity, specificity, and PPV of anti-citrullinated antibodies for overall JIA population and JIA subtypes

\begin{tabular}{|c|c|c|c|}
\hline & Sensitivity (\%) & Specificity (\%) & PPV (\%) \\
\hline & With $95 \% \mathrm{Cl}$ & With $95 \% \mathrm{Cl}$ & With $95 \% \mathrm{Cl}$ \\
\hline \multicolumn{4}{|c|}{ Anti-citrullinated type II collagen } \\
\hline \multicolumn{4}{|l|}{ Antibodies (> 3.030D) } \\
\hline Overall $(n=95)$ & $25.8(17.4-36.4)$ & $86.2(67.4-95.5)$ & $85.2(65.4-95.1)$ \\
\hline Poly RF-positive $(n=16)$ & $12.5(2.2-39.6)$ & $71.2(59.3-80.9)$ & $8.7(1.5-29.5)$ \\
\hline Poly RF-negative $(n=36)$ & $28.1(14.4-47.0)$ & $75.4(61.9-85.5)$ & $39.1(20.5-61.2)$ \\
\hline Oligoarthritis $(n=24)$ & $30.4(14.1-53.0)$ & $75.8(63.4-85.1)$ & $30.4(14.1-53.0)$ \\
\hline Systemic-Onset $(n=13)$ & $16.7(2.9-49.1)$ & $72.7(61.2-82.1)$ & $8.7(1.5-29.5)$ \\
\hline \multicolumn{4}{|c|}{ Anti-citrullinated vimentin } \\
\hline \multicolumn{4}{|c|}{ Antibodies 1-16 (> 0.790D) } \\
\hline Overall $(n=95)$ & $10.9(5.6-19.5)$ & $86.2(67.4-95.5)$ & $71.4(42.0-90.4)$ \\
\hline Poly RF-positive $(n=16)$ & $6.3(0.3-32.2)$ & $88.2(78.2-94.1)$ & $10.0(0.5-45.9)$ \\
\hline Poly RF-negative ( $n=36$ ) & $9.1(2.4-25.5)$ & $88.1(76.5-94.7)$ & $30.0(8.1-64.6)$ \\
\hline Oligoarthritis $(n=24)$ & $12.5(3.3-33.5)$ & $89.7(79.3-95.4)$ & $30.0(8.1-64.6)$ \\
\hline Systemic-Onset $(n=13)$ & $23.1(6.2-54.0)$ & $91.1(82.0-96.1)$ & $30.0(8.1-64.6)$ \\
\hline \multicolumn{4}{|c|}{ Anti-citrullinated vimentin } \\
\hline \multicolumn{4}{|c|}{ Antibodies 59-74 (> 0.81OD) } \\
\hline Overall $(n=95)$ & $7.8(3.5-15.9)$ & $89.7(71.5-97.3)$ & $70.0(35.4-91.9)$ \\
\hline Poly RF-positive $(n=16)$ & $14.3(2.5-43.8)$ & $93.4(84.7-97.6)$ & $28.6(5.1-69.7)$ \\
\hline Poly RF-negative ( $n=36)$ & $6.1(1.1-21.6)$ & $91.2(80.0-96.7)$ & $28.6(5.1-69.7)$ \\
\hline Oligoarthritis $(n=24)$ & $8.3(1.5-28.5)$ & $92.4(82.5-97.2)$ & $28.6(5.1-69.7)$ \\
\hline Systemic-Onset $(n=13)$ & $7.7(0.4-37.9)$ & $92.2(83.2-96.8)$ & $14.3(0.8-58.0)$ \\
\hline
\end{tabular}

Cl: Confidence interval; OD: Optical density; PPV: Positive predictive value; RF: Rheumatoid factor. Subtypes with small sample size were not included in the subtype analysis.

patients and $14 \%$ of systemic-onset JIA patients, with Myers et al. [25] reporting that $72 \%$ of their JIA patient population had a significant inflammatory $\mathrm{T}$ cell response to type II collagen. These previously reported findings may explain the higher prevalence of native type II collagen antibodies (17.9\%) in our JIA patient population. To date, there is no published data on the prevalence or significance of anti-citrullinated type II collagen antibodies in JIA, while this has been well-studied in adult RA [11, 12, 16]. The prevalence of autoantibodies to citrullinated type II collagen antibodies appears to be higher in adult RA patients compared to our JIA population, with one study detecting them in $78.5 \%$ of their RA patients [11], and another in $40.4 \%$ of RA patients [16]. It would be of interest to evaluate anti-citrullinated type II collagen antibody levels in the synovium of JIA patients, as it was shown in adult RA patients that citrullinated type II collagen was produced in the inflamed articular synovium [11]. Anti-citrullinated type II collagen antibodies were one of the most commonly observed citrullinated autoantibody in this JIA population, which also demonstrated a relatively high specificity for JIA (86.2\%). Based on these findings, antibodies to both native and citrullinated type II collagen may play a role in JIA.
There were some limitations to the present study, including the small size of the healthy population used to generate cut-off values for anti-citrullinated type II collagen and vimentin antibodies. However, the prevalence of citrullinated autoantibodies in our cohort was similar to findings in previous studies [14, 15]. The enthesitis-related and psoriatic arthritis groups were rather small, with larger populations needed in future studies to confirm the significance of citrullinated type II collagen and vimentin autoantibodies in these subtypes. With the addition of more enthesitis-related arthritis patients in future studies, it will be interesting to determine if the high prevalence of anti-citrullinated type II collagen antibodies remains, or if this was a reflection of small sample size. Longitudinal studies with new or early-onset JIA will be necessary to further characterize the role these citrullinated autoantibodies play in aggressive disease, including joint damage.

\section{Conclusions}

The present study showed that anti-citrullinated type II collagen and anti-citrullinated vimentin antibodies are present in JIA patients. The anti-citrullinated type II collagen and fibrinogen antibodies were the most 
frequently detected of the citrullinated autoantibodies in this JIA population. Overall, the presence of citrullinated autoantibodies in JIA patients is highly diverse, with several patterns of anti-citrullinated autoantibodies noted.

\section{Abbreviations}

BSA: Bovine serum albumin; CCP: Cyclic citrullinated peptide; CIA: Collageninduced arthritis; CRP: C-reactive protein; DAS: Disease activity score; DTT: Dithiothreitol; ELISA: Enzyme-linked immunosorbent assay; ESR: Erythrocyte sedimentation rate; HRP: Horseradish peroxidase; ILAR: International League of Associations for Rheumatology; JIA: Juvenile idiopathic arthritis; MCV: Mutated citrullinated vimentin; OD: Optical density; PAD: Peptidyl arginine deiminase; PBS: Phosphate buffered saline; PPV: Positive predictive value; RA: Rheumatoid arthritis; RIA: Radioimmunoassay buffer; RF: Rheumatoid factor; RT: Room temperature; SLE: Systemic lupus erythematosus; SPSS: Statistical package social sciences; TMB: Tetramethylbenzidine.

\section{Competing interests}

The authors declare that they have no competing interests.

\section{Authors' contributions}

BEG conceived the study, participated in the design of the study, performed immunoassays, performed data analysis, and drafted the manuscript. AKC participated in the design of the study. TLM conceived the study, participated in the design of the study, and drafted the manuscript. All authors have read and approved the final manuscript.

\section{Authors' information}

BEG, M.S., is a Research Assistant at the Division of Adult and Pediatric Rheumatology, Saint Louis University School of Medicine. AKC, Ph.D., is a Visiting Professor at the Division of Adult and Pediatric Rheumatology, Saint Louis University School of Medicine. TLM, M.D., is the Director, Division of Adult and Pediatric Rheumatology and a Professor of Internal Medicine, Pediatrics, and Molecular Microbiology and Immunology at Saint Louis University School of Medicine.

\section{Funding}

Funding provided by the Campbell-Avery Charitable Trust, the Dorr Family Charitable Trust, and the Lupus/Juvenile Arthritis Research Group of Saint Louis.

Received: 19 April 2013 Accepted: 24 August 2013

Published: 29 August 2013

\section{References}

1. Aletha D, Neogi T, Silman AJ, Funovits J, Felson DT, Bingham CO III, Birnbaum NS, Burmester GR, Bykerk VP, Cohen MD, Combe B, Costenbader KH, Dougados M, Emery P, Ferraccioli G, Hazes JM, Hobbs K, Huizinga TW, Kavanaugh A, Kay J, Kvien TK, Laing T, Mease P, Ménard HA, Moreland LW, Naden RL, Pincus T, Smolen JS, Stanislawska-Biernat E, Symmons D, Tak PP, Upchurch KS, Vencovsky J, Wolfe F, Hawker G: Rheumatoid arthritis classification criteria: an American college of rheumatology/European league against rheumatism collaborative initiative. Ann Rheum Dis 2010, 2010(69):1580-1588.

2. Petty RE, Southwood TR, Manners P, Baum J, Glass DN, Goldenberg J, He X Maldonado-Cocco J, Orozco-Alcala J, Prieur AM, Suarez-Almazor ME, Woo P: International League of Associations for Rheumatology: International League of Associations for Rheumatology classification of juvenile idiopathic arthritis: second revision, Edmonton, 2001. J Rheumatol 2004, 31:390-392.

3. Klareskog L, Rönnelid J, Lundberg K, Padyukov L, Alfredsson L: Immunity to citrullinated proteins in rheumatoid arthritis. Annu Rev Immunol 2008, 26:651-675.

4. Omar A, Abo-Elyoun I, Hussein H, Nabih M, Atwa H, Gad S, Emad Y. Anti-cyclic citrullinated peptide (anti-CCP) antibody in juvenile idiopathic arthritis (JIA): correlations with disease activity and severity of joint damage (a multicenter trial). Joint Bone Spine 2013, 80:38-43.
5. Habib HM, Mosaad YM, Youssef HM: Anti-cyclic citrullinated peptide antibodies in patients with juvenile idiopathic arthritis. Immuno Invest 2008, 37:849-857.

6. Gilliam BE, Chauhan AK, Low JM, Moore TL: Measurement of biomarkers in juvenile idiopathic arthritis patients and their significant association with disease severity: a comparative study. Clin Exp Rheumatol 2008, 26:492-497.

7. Avčin T, Cimaz R, Falcini F, Zulian F, Martini G, Simonini G, Porenta-Besic V, Cecchini G, Borghi MO, Meroni PL: Prevalence and clinical significance of anti-cyclic citrullinated peptide antibodies in juvenile idiopathic arthritis. Ann Rheum Dis 2002, 61:608-611.

8. Kasapcopur O, Altun S, Aslan M, Karaarslan S, Kamburoglu-Göksel A, Saribas S, Arisoy N, Kocazeybek B: Diagnostic accuracy of anti-cyclic citrullinated peptide antibodies in juvenile idiopathic arthritis. Ann Rheum Dis 2004, 63:1687-1689.

9. Gilliam BE, Reed MR, Chauhan AK, Dehlendorf AB, Moore TL: Evidence of fibrinogen as a target of citrullination in IgM rheumatoid factor-positive polyarticular juvenile idiopathic arthritis. Pediatr Rheumatol Online J 2011 9:8.

10. Syed RH, Gilliam BE, Moore TL: Prevalence and significance of isotypes of anti-cyclic citrullinated peptide antibodies in juvenile idiopathic arthritis. Ann Rheum Dis 2008, 67:1049-1051.

11. Yoshida M, Tsuji M, Kurosaka D, Kurosaka D, Yasuda J, Ito Y, Nishizawa T, Yamada A: Autoimmunity to citrullinated type II collagen in rheumatoid arthritis. Mod Rheumatol 2006, 16:276-281.

12. Uysal H, Bockerman R, Nandakumar KS, Sehnert B, Bajtner E, Engström $\AA$ Serre G, Burkhardt H, Thunnissen MM, Holmdahl R: Structure and pathogenicity of antibodies specific for citrullinated collagen type II in experimental arthritis. J Exp Med 2009, 206:449-462.

13. Van Steendam K, Tilleman K, Deforce D: The relevance of citrullinated vimentin in the production of antibodies against citrullinated proteins and the pathogenesis of rheumatoid arthritis. Rheumatology 2011, 50:830-837.

14. Kuna AT, Lamot L, Miler M, Harjacek M, Simundic AM, Vrkic N: Antibodies to mutated citrullinated vimentin and antibodies to cyclic citrullinated peptides in juvenile idiopathic arthritis. Clin Chem Lab Med 2009, 47:1525-1530.

15. Morbach H, Dannecker H, Karkau T, Girschick HJ: Prevalence of antibodies against mutated citrullinated vimentin and cyclic citrullinated peptide in children with juvenile idiopathic arthritis. Clin Exp Rheumatol 2010, 28:800.

16. Burkhardt H, Sehnert B, Bockerman R, Engström Å, Kalden JR, Holmdahl R: Humoral immune response to citrullinated collagen type II determinants in early rheumatoid arthritis. Eur J Immunol 2005, 35:1643-1652.

17. Ioan-Facsinay A, Willemze A, Robinson DB, Peschken CA, Markland J, van der Woude D, Elias B, Ménard HA, Newkirk M, Fritzler MJ, Toes RE, Huizinga TW, El-Gabalawy HS: Marked differences in fine specificity and isotype usage of the anti-citrullinated protein antibody in health and disease. Arthritis Rheum 2008, 58:3000-3008.

18. Snir $\mathrm{O}$, Widhe $M$, Hermansson M, von Spee C, Lindberg J, Hensen $S$, Lundberg K, Engström A, Venables PJ, Toes RE, Holmdahl R, Klareskog L, Malmström V: Antibodies to several citrullinated antigens are enriched in the joints of rheumatoid arthritis patients. Arthritis Rheum 2010, 62:44-52.

19. Nielen MM, van der Horst AR, van Schaardenburg $D$, van der HorstBruinsma IE, van de Stadt RJ, Aarden L, Dijkmans BA, Hamann D: Antibodies to citrullinated human fibrinogen (ACF) have diagnostic and prognostic value in early arthritis. Ann Rheum Dis 2005, 64:1199-1204.

20. Kinloch A, Tatzer V, Wait R, Peston D, Lundberg K, Donatien P, Moyes D, Taylor PC, Venables PJ: Identification of citrullinated a-enolase as a candidate autoantigen in rheumatoid arthritis. Arthritis Res Ther 2005 7:R1421-R1429.

21. Lundberg K, Kinloch A, Fisher BA, Wegner N, Wait R, Charles P, Mikuls TR, Venables PJ: Antibodies to citrullinated $\alpha$-enolase peptide 1 are specific for rheumatoid arthritis and cross-react with bacterial enolase. Arthritis Rheum 2008, 58:3009-3019.

22. Innala L, Kokkonen H, Eriksson C, Jidell E, Berglin E, Rantapää-Dahlqvist S: Antibodies against mutated citrullinated vimentin are a better predictor of disease activity at 24 months in early rheumatoid arthritis than antibodies against cyclic citrullinated peptides. J Rheumatol 2008, 35:1002-1008.

23. van der Linden MPM, van der Woude D, loan-Facsinay A, Levarht EW, Stoeken-Rijsbergen G, Huizinga WJ, Toes RE, van der Helm-van Mil AH: 
Value of anti-modified citrullinated vimentin and third-generation anticyclic citrullinated peptide compared with second-generation anti-cyclic citrullinated peptide and rheumatoid factor in predicting disease outcome in undifferentiated arthritis and rheumatoid arthritis. Arthritis Rheum 2009, 60:2232-2241.

24. Lindsley CB, Janecek LL, Horton WA, Lindsley HB: IgG anticollagen antibodies in sera of patients with childhood rheumatic diseases [abstract]. Arthritis Rheum 1980, 23:S56.

25. Myers LK, Higgins GC, Finkel TH, Reed AM, Thompson JW, Walton RC, Hendrickson J, Kerr NC, Pandya-Lipman RK, Shlopov BV, Stastny P,

Postlethwaite AE, Kang AH: Juvenile arthritis and autoimmunity to type II collagen. Arthritis Rheum 2001, 44:1775-1781.

26. Barnett ML, Combitchi D, Trentham DE: A pilot trial of oral type II collagen in the treatment of juvenile rheumatoid arthritis. Arthritis Rheum 1996, 39:623-628.

doi:10.1186/1546-0096-11-31

Cite this article as: Gilliam et al:: Evaluation of anti-citrullinated type II collagen and anti-citrullinated vimentin antibodies in patients with juvenile idiopathic arthritis. Pediatric Rheumatology 2013 11:31.

\section{Submit your next manuscript to BioMed Central and take full advantage of:}

- Convenient online submission

- Thorough peer review

- No space constraints or color figure charges

- Immediate publication on acceptance

- Inclusion in PubMed, CAS, Scopus and Google Scholar

- Research which is freely available for redistribution 